\title{
Weaning from Mechanical Ventilation in Children: Are We Getting It Right?
}

\author{
Mullai Baalaaji AR@ \\ Indian Journal of Critical Care Medicine (2021): 10.5005/jp-journals-10071-23974
}

Respiratory disorders are one of the major reasons for admission into the Pediatric Intensive Care Unit (PICU), and mechanical ventilation is a major intervention carried out to save lives in these children. Although mechanical ventilation is lifesaving, it is not free of complications. Airway injury, ventilator-induced lung injury, ventilator-associated pneumonia (VAP), need for sedatives, and their resultant effects can all lead to prolonged morbidity in children. Hence, it becomes imperative to identify the patient's readiness to sustain spontaneous breathing independent of a ventilator and liberate them from mechanical ventilation promptly. On the contrary, premature extubation exposes the child to risks of extubation failure, reintubation, aspiration, higher risks of VAP, and mortality. Both delayed and premature extubation result in higher complication rates, increased morbidity and mortality, and also escalating the costs involved.

The phase of transition from complete ventilatory support to complete spontaneous breathing while maintaining adequate gas exchange is referred to as "weaning from ventilation." It should be distinguished from extubation that refers to the physical removal of an endotracheal tube. Approximately $40-50 \%$ of the total ventilation duration is occupied by this weaning phase. ${ }^{1}$ The clinical decision to wean from ventilation has been traditionally based on physician's judgment and clinical experience. The steps involved in weaning and subsequent extubation include (1) assessment of the readiness to wean; (2) spontaneous breathing trial (SBT) while monitoring the child for possible weaning failure; and (3) extubation. Readiness to wean is assessed once the child is stabilized and the primary indication for initiating ventilation is reversed. The parameters considered are (i) reversal of the primary reason for ventilation; (ii) ability to maintain oxygenation and ventilation with low $\mathrm{FiO}_{2}$ and positive end-expiratory pressure (PEEP); (iii) hemodynamic stability; (iv) acceptable consciousness level and airway protective reflexes; (v) adequate spontaneous respiratory efforts; (vi) sedation level; and (vii) fluid balance. This assessment is done daily, and eligible children are then weaned from ventilation. ${ }^{2}$

Once it is decided that the child is ready to be weaned, the most common approach is a gradual decrease in ventilatory support and assessing the readiness to extubate once they tolerate a low level of ventilator support. The alternative approach is to assess the readiness to extubate as soon as the patient meets the criteria to initiate the ventilator weaning process. SBT is used to assess the ability of a patient to maintain acceptable gas exchange with minimal/no ventilator assistance. Pressure support (PS) with PEEP, Continuous Positive Airway Pressure (CPAP), or a T-piece trial are the various accepted SBTs. Once the child is able to tolerate one of the three SBTs without
Department of Pediatric Critical Care, Kovai Medical Center and Hospital, Coimbatore, Tamil Nadu, India

Corresponding Author: Mullai Baalaaji AR, Department of Pediatric Critical Care, Kovai Medical Center and Hospital, Coimbatore, Tamil Nadu, India, Phone: +91 9855050822, e-mail: drmullaibaalaaji@ gmail.com

How to cite this article: Baalaaji ARM. Weaning from Mechanical Ventilation in Children: Are We Getting It Right? Indian J Crit Care Med 2021;25(9):974-975.

Source of support: Nil

Conflict of interest: None

any increase in effort of breathing, they can be extubated, provided, protective airway reflexes are intact and are able to handle tracheal secretions. It was previously believed that breathing through a narrow endotracheal tube by infants imposes additional work of breathing and PS is needed to overcome this presumed additional work, although it has been proven to be not the case. ${ }^{3,4}$ It is also important to realize that provision of "minimal PS" offers substantial ventilatory assistance to the child and does not truly represent complete spontaneous breathing. A T-piece or CPAP $\leq 5 \mathrm{~cm} \mathrm{H}_{2} \mathrm{O}$ provides the best assessment of unassisted effort of breathing. ${ }^{5,6}$

This entire process of weaning assessment and subsequent extubation could be protocolized or driven by individual physician. Protocolized weaning aims at having a uniform set of rules to reduce unwanted variability in the clinical practice. The use of protocols may also have the potential to enable nonmedical healthcare personnel, namely the nurses and respiratory therapists to take up the responsibility in weaning, thus initiate the weaning process at an appropriate time and potentially reduce the risks and costs associated with unnecessary prolongation of ventilation duration. ${ }^{7}$

In the current study, the authors have compared the duration of mechanical ventilation and extubation failure rates using two different approaches: protocolized weaning using PS SBT followed by T-piece vs nonprotocolized physician-driven weaning, which was synchronized intermittent mandatory ventilation followed by the T-piece trial. ${ }^{8}$ The children were randomized once they met the eligibility criteria for SBT. Prior to extubation, children in both the groups were given a T-piece trial of 2 hours duration. A majority of children (38/40) in both the groups could be extubated, and no significant difference could be demonstrated between the two groups. Also, the ventilation duration was similar between the two groups.

(c) Jaypee Brothers Medical Publishers. 2021 Open Access This article is distributed under the terms of the Creative Commons Attribution 4.0 International License (https://creativecommons.org/licenses/by-nc/4.0/), which permits unrestricted use, distribution, and non-commercial reproduction in any medium, provided you give appropriate credit to the original author(s) and the source, provide a link to the Creative Commons license, and indicate if changes were made. The Creative Commons Public Domain Dedication waiver (http://creativecommons.org/publicdomain/zero/1.0/) applies to the data made available in this article, unless otherwise stated. 
Previous studies in children gave conflicting results with respect to protocolized weaning. In the study by Foronda et al., children randomized to SBT protocol using PS with PEEP had a significant reduction in average ventilation duration compared to standard care. ${ }^{9}$ In another study conducted by Ferreira et al, during the postoperative period following cardiac surgery, the SBT group had a greater extubation success and shorter PICU length of stay compared to the control group. ${ }^{10} \mathrm{~A}$ few other randomized controlled trials did not find significant differences in the duration of ventilation or reintubation rates between protocolized and control groups. ${ }^{11,12}$ The results of these studies are not generalizable due to the heterogeneous study population, varying practices of weaning protocol, and different end points chosen as primary outcome measures.

While comparing the different modalities that assess weaning and extubation in children, it is essential to understand the differences in the terminologies-extubation failure and weaning failure. Extubation failure is defined as a requirement for reintubation within 48 hours of extubation. In children, one of the major reasons for reintubation is upper airway obstruction due to injury or edema and while, it denotes extubation failure, it cannot be termed as weaning failure. On similar grounds, patients who are electively initiated on noninvasive ventilation postextubation cannot be termed as successful weaning or "complete liberation from ventilator" but they might have been successfully extubated.

The current study has demonstrated that PS SBT could be utilized to assess readiness to extubate; however, the authors have also performed additional T-piece trials following PS SBT prior to extubation. Also, the shorter weaning duration in the control group could be due to decisions being taken by the Pediatric Intensivist in the unit. Although data in adults support the use of a dedicated weaning protocol that results in faster weaning, the data are still less clear in children. ${ }^{13}$ The reasons for this disparity could be due to shorter duration of mechanical ventilation and lower extubation failure rates in children. ${ }^{14}$

Thus, the process of weaning of children from mechanical ventilation continues to involve as much an art as science. Consistent and daily application of practice such as sedation holidays, assessing readiness to wean, and SBTs would be needed to liberate them from mechanical ventilation at appropriate time point. The exact way of conducting the various SBTs, the relation with weaning success, and the effect on ventilator-free days or length of stay still remain unanswered.

\section{ORCID}

Mullai Baalaaji AR @ https://orcid.org/0000-0003-1746-1586

\section{References}

1. Newth CL, Venkataraman S, Wilson D, Meert K, Harrison R, Dean JM, et al. Weaning and extubation readiness in pediatric patients. Pediatr Crit Care Med 2009;10(1):1-11. DOI: 10.1097/PCC.0b013e318193724d.
2. Newth $\mathrm{CL}$, Hotz JC, Khemani RG. Ventilator liberation in the Pediatric ICU. Respir Care. 2020;65(10):1601-1610. DOI: 10.4187/respcare.07810.

3. Hammer J, Newth C. Influence of endotracheal tube diameter on forced deflation flow-volume curves in rhesus monkeys. Eur Respir J 1997;10(8):1870-1873. DOI: 10.1183/09031936.97.10081870.

4. Jarreau PH, Louis B, Dassieu G, Desfrere L, Blanchard PW, Moriette G, et al. Estimation of inspiratory pressure drop in neonatal and pediatric endotracheal tubes. J Appl Physiol 1999;87(1):36-46. DOI: 10.1152/ jappl.1999.87.1.36.

5. Khemani RG, Hotz J, Morzov R, Flink RC, Kamerkar A, LaFortune M, et al. Pediatric extubation readiness tests should not use pressure support. Intensive Care Med 2016;42(8):1214-1222. DOI: 10.1007/ s00134-016-4387-3.

6. Khemani RG, Newth C. CPAP alone best estimates post-extubation effort during spontaneous breathing trials in children. Intensive Care Med 2017;43(1):150-151. DOI: 10.1007/s00134-016-4584-0.

7. Blackwood B, Murray M, Chisakuta A, Cardwell CR, O'Halloran P, Cochrane Emergency and Critical Care Group. Protocolized versus nonprotocolized weaning for reducing the duration of invasive mechanical ventilation in critically ill paediatric patients. Cochrane Database Syst Rev 2013;2013(7):CD009082. DOI: 10.1002/14651858.CD009082.pub2.

8. Kishore R, Jhamb U. Effect of Protocolized Weaning and Spontaneous Breathing Trial vs Conventional Weaning on Duration of Mechanical Ventilation: A Randomized Controlled Trial. Indian J Crit Care Med 2021;25(9):1059-1065.

9. Foronda F, Troster EJ, Farias JA, Barbas CS, Ferraro AA, Faria LS, et al. Impact of daily evaluation and spontaneous breathing test on the duration of pediatric mechanical ventilation: a randomized controlled trial. Crit Care Med 2011;39(11):2526-2533. DOI: 10.1097/ CCM.0b013e3182257520.

10. Ferreira FV, Sugo EK, Aragon DC, Carmona F, Carlotti APCP. Spontaneous breathing trial for prediction of extubation success in pediatric patients following congenital heart surgery: a randomized controlled trial. Pediatr Crit Care Med 2019;20(10):940-946. DOI: 10.1097/PCC.0000000000002006.

11. Randolph AG, Wypij D, Venkataraman ST, Hanson JH, Gedeit RG, Meert $\mathrm{KL}$, et al. Effect of mechanical ventilator weaning protocols on respiratory outcomes in infants and children: a randomized controlled trial. JAMA 2002;288(20):2561-2568. DOI: 10.1001/ jama.288.20.2561.

12. Schultz TR, Lin RJ, Watzman HM, Durning SM, Hales R, Woodson A, et al. Weaning children from mechanical ventilation: a prospective randomized trial of protocol-directed versus physician-directed weaning. Respir Care 2001;46(8):772-782. PMID: 11463367.

13. Blackwood B, Alderdice F, Burns KEA, Cardwell CR, Lavery G, $\mathrm{O}$ 'Halloran P. Protocolized versus non-protocolized weaning for reducing the duration of mechanical ventilation in critically ill adult patients. Cochrane Database Syst Rev 2010;(5). DOI: 10.1002/14651858. CD006904.pub2.

14. Rimensberger PC, Cheifetz IM, Kneyber MCJ. The top ten unknowns in paediatric mechanical ventilation. Intensive Care Med 2018;44: 366-370. DOI: 10.1007/s00134-017-4847-4. 